\title{
Early sensitisation to food allergents in Lithuanian birth cohort
}

\author{
Indre Butiene ${ }^{1 *}$, Odilija Rudzeviciene ${ }^{2}$, Ruta Dubakiene ${ }^{1}$ \\ From Food Allergy and Anaphylaxis Meeting 2011 \\ Venice, Italy. 17-19 February 2011
}

\section{Background}

The factors responsible for the induction of allergic disease at an early age have not been completely identified. Data about maternal factors during pregnancy and early sensitization to food allergens are limited. Aim: To determine the prevalence of food sensitization in children under 6 months of age and to determine relationship between maternal avoidance of allergenic foods, maternal disease, use of antibiotic, tobacco smoke during pregnancy and early sensitization to food allergens.

\section{Methods}

The analysis was based on data of 1558 subjects from a EuroPrevall Lithuanian birth cohort study ( EU 6 FP project "EuroPrevall:). Children younger than 6 months of age and sensitized to food allergens and their controls were analyzed. Information was collected using parental questionnaires filled at the day of recruitment, 12 months questionnaire and physical examination form, results of SPT and SIgE analysis.

\section{Results}

Early sensitization to food allergens was detected in 20 children under 6 months of age $(1.3 \%, 1558) .15$ (75\%) symptomatic subjects were sensitized to milk, positive SPT was found in 5, elevated sIgE in 4 , only immediate or repetitive symptoms were reported in 8 patients. 12 (60\%) symptomatic subjects were sensitized to egg, positive SPT was found in 9, elevated SIgE in 7, only symptoms were reported in 1 patient. Sensitization to wheat was confirmed in 2 patients by SPT and reported symptoms, to peanut - in 1 subject by elevated sIgE. The food allergy was confirmed by positive DBPCFC in 4 infants - 2 for milk, 1 - egg, 1 - wheat. There were found no significant impact of maternal diseases $(\mathrm{p}=$

${ }^{1}$ Vilnius University, Faculty of medicine, Vilnius, Lithuania

Full list of author information is available at the end of the article

$0.34)$, use of antibiotics $(\mathrm{p}=0.7)$, tobacco smoke $(\mathrm{p}=$ 0.25 ) during pregnancy on early sensitization to food allergens. Maternal avoidance of milk and egg products during pregnancy, as well as use in elevated amounts of the product was not related to early sensitization to milk and egg allergens $(\mathrm{p}=0.38)$.

\section{Conclusions}

The prevalence of food sensitization in children under 6 months of age was $1.3 \%$. Maternal diet and disease, use of antibiotic, tobacco smoke during pregnancy had no significant impact on early sensitization to food allergens.

\section{Author details}

${ }^{1}$ Vilnius University, Faculty of medicine, Vilnius, Lithuania. ${ }^{2}$ Vilnius University, Clinic of Children's Diseases, Vilnius, Lithuania.

Published: 12 August 2011

\section{doi:10.1186/2045-7022-1-S1-O4}

Cite this article as: Butiene et al.: Early sensitisation to food allergents in Lithuanian birth cohort. Clinical and Translational Allergy 2011 1(Suppl 1): 04

Submit your next manuscript to BioMed Central and take full advantage of:

- Convenient online submission

- Thorough peer review

- No space constraints or color figure charges

- Immediate publication on acceptance

- Inclusion in PubMed, CAS, Scopus and Google Scholar

- Research which is freely available for redistribution

\section{Biomed Central}

(c) 2011 Butiene et al; licensee BioMed Central Ltd. This is an open access article distributed under the terms of the Creative Commons Attribution License (http://creativecommons.org/licenses/by/2.0), which permits unrestricted use, distribution, and reproduction in any medium, provided the original work is properly cited. 